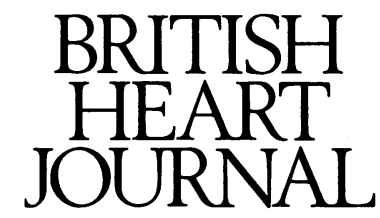

Editorial

\title{
Ultrasound and coarctation of the aorta
}

Initial reports of cross sectional echocardiography in the diagnosis of coarctation of the aorta were very promising, ${ }^{12}$ with the technique allowing operation to be carried out without invasive investigation in many patients. ${ }^{3}$ As experience grew, however, it became clear that high quality images of the aortic arch are not universally obtainable, that cross sectional echocardiography does not always provide an answer, and that occasionally it may even lead to false positive diagnosis of an aortic arch obstruction. ${ }^{4}$ Doppler ultrasound was welcomed as a solution. Published studies were reassuring; calculation of the pressure drop across the site of coarctation by the modified Bernoulli equation was reported to reflect accurately both the blood pressure difference between the upper and lower limbs ${ }^{56}$ and the invasively measured pressure gradient, ${ }^{7-9}$ but again experience proved this approach to be too simplistic. Just as for other cardiovascular stenoses, gradients estimated by Doppler represent maximum instantaneous values rather than the traditionally used difference between peak systolic pressures on both sides of an obstruction. The differences between these two measurements may be considerable and clinically important. ${ }^{10}$

Disappointingly, even when these differences are taken into account, in some patients there is poor agreement between the coarctation gradients measured invasively and by Doppler. ${ }^{112}$ Various factors are responsible for this. It can be difficult to align the Doppler beam with flow, complex flow dynamics in the aortic arch may invalidate some of the assumptions made in the calculation of pressure drop, and a tunnel like stenosis when present is a less suitable subject for Doppler calculations than a discrete obstruction. ${ }^{13}$ Furthermore, it is now clear that severe obstruction of the aortic arch may be associated with normal or near normal aortic flow velocities depending on the state of the ductus arteriosus ${ }^{1214}$ or the presence of extensive collaterals. ${ }^{15}$

Use of the pressure gradient as an indicator of severity of valve stenosis has long been recognised as being fraught with problems, largely related to the dependence of gradient on blood flow. Similar confusion about the value of the pressure gradient in coarctation is understandable because this too is dependent on factors other than the degree of obstruction. Stroke volume, the presence of a ductus arteriosus, and the extent of the collateral supply to the descending aorta are all important factors. Thus many of the difficulties associated with the assessment of the severity of valve stenosis ${ }^{16}$ are common to the assessment of coarctation and could be avoided, at least in theory, if the effective orifice area at the site of the coarctation could be estimated.

The concept of pressure decay (a square function of velocity decay) across an obstruction to flow as an indicator of effective orifice area has long been applied to fluid dynamics and was first applied in invasive cardiology to mitral stenosis, ${ }^{17}$ later being adapted for use with Doppler ultrasound..$^{18}$ Disappointingly, like most single variables in heart disease, pressure decay across the mitral valve is affected by factors other than stenosis-such as ventricular compliance and aortic regurgitation.

Dr Carvalho and her colleagues ( $p$ 133) confirmed that the Doppler pressure drop alone cannot always be relied upon to predict the severity of coarctation of the aorta. They propose an additional measurement of diastolic flow velocity decay-the time to half peak diastolic velocity. This is defined as the time taken for flow velocity to fall from its peak value in diastole (measured at the end of the $T$ wave of the electrocardiogram) to half this value. Prolonged flow deceleration in coarctation has long been recognised as diagnostically important ${ }^{619-21}$ but little effort has been made to introduce a simple quantitative measurement of it, such as the time to half peak diastolic velocity. The combination of this measurement with peak systolic velocity considerably improved both the test sensitivity and the predictive value of a negative test compared with either measurement used alone in the patients studied.

There seems little doubt that pressure (or velocity) decay across the aortic arch in coarctation will also be affected by factors such as vascular resistance, the competence of the aortic valve, the presence of a ductus arteriosus, and the extent of collateral blood supply to the descending aorta. In the absence of these complicating factors, the combination of measurements of peak flow velocity and flow velocity decay is clearly useful. However, when complicating factors are present uncertainty will still arise, and then the best reference standard is still probably angiographic measurement of the aortic lumen as used by Carvalho et al. Even angiography may be difficult to interpret, however, because it is dependent on arbitrarily defined criteria of severity mainly relating to anatomical features. The importance of careful consideration of physiology as well as anatomy was emphasised by studies during exercise after operation for coarctation. Some alarming physiological changes may be seen with exercise even when there are no striking signs of residual or recurrent coarctation at rest. $^{22-25}$

Non-invasive assessment of the severity of coarctation may be enhanced by measurement of velocity decay as well as peak flow velocity, but even the combination of these two measurements will not provide an answer in every patient. Further improvement in diagnosis is clearly desirable and it is hoped will prove possible with continued attempts to develop a combined anatomical and physiological approach that should involve exercising the patient.

Department of Paediatric Cardiology,

JOHN L GIBBS Killingbeck Hospital,

York Road,

Leeds LS14 6UQ 
1 Huhta JC, Gutgesell JP, Latson LA, Huffines FD. Two dimensional echocardiographic assessment of the aorta in infants and children with congenital heart disease. Circulation 1984;70:417-24.

2 Smallhorn JF, Huhta JC, Adams PA, Anderson RH, Wilkinson JL, Macartney FJ. Cross-sectional echocardiographic assessment of coarctation in the sick neonate and infant. Br Heart $J$ 1983;50:349-61.

3 Duncan WJ, Ninomiya K, Cook DH, Rowe RD. Noninvasive diagnosis of neonatal coarctation and associated anomalies using two-dimensional echocardiography. Am Heart J 1983;106:63-9.

4 Nihoyannopoulos P, Karas S, Sapsford RN, Hallidie-Smith K, Foale R. Accuracy of two-dimensional echocardiography in the diagnosis of aortic Accuracy of two-dimensional echocardiography in the

5 Wyse RKH, Robinson PJ, Deanfield JE, Tunstall Pedoe DS, Macartney FJ. Use of continuous wave Doppler ultrasound velocimetry to assess the severity of coarctation of the aorta by measurement of aortic flow velocities. Br Heart J 1984;52:278-83.

6 Barth H, Hassberg D, Schmalz AA, Steil I, Apitz J. Continuous-wave Doppler velocimetry and blood pressure difference in coarctation of the aorta a simultaneous correlative study in 52 children. Herz 1987;12: 217-25.

7 Robinson PJ, Wyse RKH, Deanfield JE, Franklin R, Macartney FJ. Continuous wave Doppler velocimetry as an adjunct to cross sectional echocardiography in the diagnosis of critical left heart obstruction in neonates. Br Heart J 1984;52:552-6.

8 Hoadley SD, Duster MC, Miller JF, Murgo JP. Pulsed Doppler study of coarctation of the aorta: demonstration of a continuous Doppler frequency shift. Pediatr Cardiol 1986;6:275-7.

9 Marx GR, Allen HD. Accuracy and pitfalls of Doppler evaluation of the pressure gradient in aortic coarctation. J Am Coll Cardiol 1986;7: the press

10 Currie PJ, Hagler DJ, Seward JB, et al. Instantaneous pressure gradient: a simultaneous Doppler and dual catheter correlative study. J Am Coll simultaneous Doppler

11 Stevenson JG, French JW, Kawabori I. Doppler measurement of coarctation gradients [Abstract]. Circulation 1985;72 (part II):III-5.

12 Houston AB, Simpson IA, Pollock JCS, Jamieson MPG, Doig WB Coleman EN. Doppler ultrasound in the assessment of severity of coarctation of the aorta and interruption of the aortic arch. Br Heart $J$ 1987;57:38-43.

13 Teirstein PS, Yock PG, Popp RL. The accuracy of Doppler ultrasound measurement of pressure gradients across irregular, dual, and tunnellike obstructions to blood flow. Circulation 1985;72:577-84.

14 Wilson N, Sutherland GR, Gibbs JL, Dickinson DF, Keeton B. Limitations of Doppler ultrasound in the diagnosis of neonatal coarctation of the aorta. Int J Cardiol 1989;23:87-9.

15 Scott PJ, Wharton GA, Gibbs JL. Failure of Doppler ultrasound to detect coarctation of the aorta. Int J Cardiol 1990 (in press).

16 Odemuyiwa O, Hall R JC. Assessing the severity of valve stenosis. Br Heart J 1986;55:117-9.

17 Libanoff AJ, Rodbard S. Atrioventricular pressure half time. Measure of mitral valve orifice area. Circulation 1968;38:144-50.

18 Hatle L, Angelsen B, Tromsdal A. Noninvasive assessment of atrioventricular pressure half-time by Doppler ultrasound. Circulation 1979; 60:1096-104.

19 Hagler DJ, Tajik AJ, Seward JB, Ritter DG. Noninvasive assessment of pulmonary valve stenosis, aortic valve stenosis and coarctation of the aor in critically ill neonates. Am J Cardiol 1986;57:369-72.

20 Shaddy RE, Snider AR, Silverman NH, Lutin W. Pulsed Doppler finding in patients with coarctation of the aorta. Circulation 1986;73:82-8.

21 Rao PS, Carey P. Doppler ultrasound in the prediction of pressure gradients across aortic coarctation. Am Heart J 1989;118:299-307.

22 Earley A, Joseph MC, Shinebourne EA, de Swiet $M$. Blood pressure and effect of exercise in children before and after surgical correction of $\overrightarrow{0}$ coarctation of aorta. Br Heart J 1980;44:411-5.

23 Freed MD, Rocchini A, Rosenthal A, Nadas AS, Castaneda AR. Exerciseinduced hypertension after surgical repair of coarctation of aorta. Am J Cardiol 1979;43:253-8.

24 Waldman ID, G. Coarctation of aort. Noninvasive physiological assessment in infants and Coarctation of aorta. Noninvasive physiological assessment in infants and children before

25 Waldman JD, Lamberti JJ, Goodman AH, et al. Coarctation in the first year of life. Patterns of postoperative effect. $J$ Thorac Cardiovasc Surg 1983; 86:9-17. 